\title{
Different Phenomena Encountered during Dilatometry of Low-density Steels
}

\author{
Pello Jimbert (D), Teresa Guraya, Idurre Kaltzakorta, Teresa Gutiérrez, Roberto Elvira, and Leili Tafaghodi Khajavi
}

Submitted: 19 March 2021 / Revised: 26 October 2021 / Accepted: 31 October 2021 / Published online: 22 November 2021

\begin{abstract}
In recent decades, highly alloyed low-density steels are being developed to reduce the weight of different automotive parts. Dilatometry can be a very useful experimental technique to understand phase transformations during heating or cooling of new low-density steel alloys. When performing dilatometry measurements some assumptions are made such as the homogeneity of the sample material tested during the experiment. In this study, dilatometry tests were performed for two different low-density steels, and the variations of the composition between the surface and the inner part of the sample were analyzed. The migration of manganese by diffusion from the interior of the samples and finally its evaporation on the surface under vacuum were observed. This compositional gradient generated in the samples may influence the veracity and interpretation of the results obtained in dilatometry when working with high manganese steel alloys. The detachment of surface grains created by this compositional change near the surface of the samples is also investigated.
\end{abstract}

Keywords dilatometry, low-density steel, Mn migration, vacuum evaporation

\section{Introduction}

The automotive industry has been working on reducing car weight without compromising passenger safety. To this end, they have adopted different strategies such as redesigning components, using high-strength steels and reducing the density of the material used in automobiles. In this last strategy, steel competes strongly with lighter metals, such as aluminum and magnesium. However, steel has the great advantage of being the most recyclable material, which is why low-density steels have been investigated in recent decades. The incorporation of light elements such as aluminum $\left(2.7 \mathrm{~g} / \mathrm{cm}^{3}\right)$ or silicon $\left(2.33 \mathrm{~g} / \mathrm{cm}^{3}\right)$ in steel $\left(7.85 \mathrm{~g} / \mathrm{cm}^{3}\right)$, can lead to a reduction in the overall density of the alloy. The addition of $1 \mathrm{wt} \%$ of aluminum can result in a total reduction of $1.5 \%$ of the steel density (Ref 1). To obtain these low-density steels, it is necessary to start from a steel base composed of iron-carbon, manganese and aluminum (Fe-C-Mn-Al) (Ref 2).

The first information on low-density steels dates back to 1933, when Korter and Ton (Ref 3) first introduced the use of the Fe-Mn-Al-C system. In 1958, Ham and Carin (Ref 4) studied the possibility of replacing $\mathrm{Ni}$ and $\mathrm{Cr}$ in stainless steels

Pello Jimbert and Teresa Guraya, Faculty of Engineering in Bilbao, University of the Basque Country UPV/EHU, Paseo Rafael Moreno "Pitxitxi" 3, 48013 Bilbao, Spain; and Idurre Kaltzakorta and Teresa Gutiérrez, Tecnalia, Basque Research and Technology Alliance (BRTA), Parque Científico y Tecnológico de Bizkaia, Astondo Bidea, 700, E-48160 Derio, Spain; Roberto Elvira, Sidenor I+D, Barrio Ugarte s/n, 48970 Basauri, Spain; and Leili Tafaghodi Khajavi, Department of Materials Science and Engineering, McMaster University, Hamilton, ON L8S 4L7, Canada. Contact e-mail: pello.jimbert@ehu.eus. with cheaper metals, such as $\mathrm{Mn}$ and $\mathrm{Al}$, due to the advantage of lower density. In the 1980s and 1990s (Ref 5-7) the substitution of $\mathrm{Ni}$ and $\mathrm{Cr}$ in stainless steel was extensively studied, but until very recently no scientific papers on low density steels have been published in a larger volume.

The interest generated in this field of application is such that in 2013, the journal Scripta Materialia (Ref 8) published a set of papers (viewpoint papers set) devoted exclusively to lowdensity steels. The number of patents filed by steel companies on low-density steels (Ref 9-16) in recent years also reflects the interest in these alloys.

For the development of new steel alloys, dilatometry is widely used to study phase transformations (Ref 17-20). Solidsolid phase transformation parameters can be studied due to the difference in specific volumes of the different phases in steel by measuring the change in length of a steel sample during a defined thermal cycle.

However, when using dilatometry, some assumptions are made that do not always hold, as studied in the scientific literature. Regarding the anisotropic deformation of measured samples, Jaramillo and Lusk (Ref 21) distinguished a significant variation in the strain amplitude during thermal processing of a low alloy steel as a function of the orientation of the sample bands. The same authors (Ref 22) and Suh et al. (Ref 23) modeled anisotropic deformation during thermal processing, and highlighted the importance of considering this phenomenon.

Thermal gradients along the sample during dilatometry measurements have also been studied. Mohapatra et al. (Ref 24) revealed that under continuous heating/cooling conditions, when the heating/cooling rate increases, the amplitude of the thermal gradient increases.

Finally, when the temperature range is above $1000{ }^{\circ} \mathrm{C}$ some metal evaporation can occur even in high vacuum dilatometers. This phenomenon, which has been reported for $\mathrm{Mn}$ and $\mathrm{Cr}$, causes heterogeneities in the microstructure (Ref 25). The Mn concentration decreases near the surface at high temperature even in vacuum or in a Helium gas atmosphere (Ref 26, 27). 
Table 1 Chemical composition in \% of weight, density and relative density reduction compared to the pure iron of the studied low-density steels

\begin{tabular}{llllllll}
\hline & Type & C & Mn & Al & Fe & Density, $\mathbf{g} / \mathbf{c m}^{\mathbf{3}}$ & Relative density reduction compared to the pure iron, \% \\
\hline Alloy 1 & Duplex & 0.35 & 3.5 & 5.8 & Bal. & 7.267 & 7.71 \\
Alloy 2 & Austenitic & 1.3 & 30 & 10 & Bal. & 6.737 & 14.44 \\
\hline
\end{tabular}
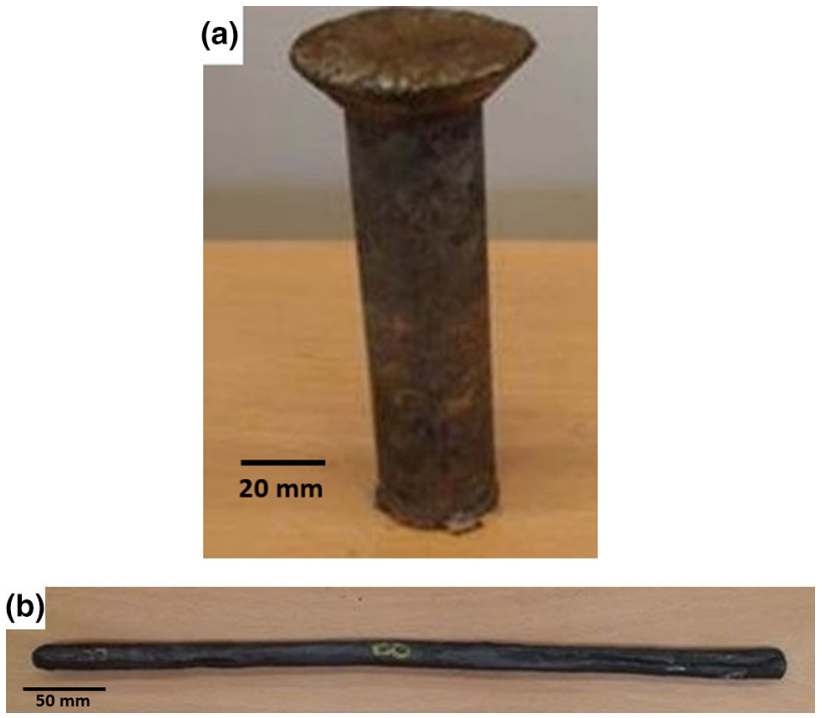

Fig. $130 \mathrm{~mm}$ diameter bar obtained from the vacuum levitation furnace (a) and this same bar after being hot forged to $14 \mathrm{~mm}$ diameter (b)

In order to study these phenomena when performing dilatometry experiments with low-density steels, two different low-density alloys, i.e., a duplex and an austenitic steel, were examined using dilatometry measurements at low cooling rates. The microstructures obtained, as well as the deposits created in the dilatometer chamber, have been analyzed. A semi-quantitative measurement of the different elements has been carried out to analyze this phenomenon of evaporation in vacuum. Decohesion of surface grains has also been observed in one of the low-density alloys studied. This phenomenon is discussed in the present manuscript.

\section{Materials and Methods}

Two low-density Fe-C-Mn-Al alloy steels were analyzed. Their chemical composition is shown in Table 1.

In this investigation, a vacuum levitation furnace consisting of a 5-turn induction coil wound around a water-cooled copper crucible, covered by a Pyrex tube and connected to a power supply assisted with vacuum and argon atmosphere was used for sample casting. The crucible is composed of copper segments converging to form a bottom hole from which molten metal can be extracted by removing a refrigerated plug to pour the molten metal into a water-cooled copper mold. These molds can have different geometries depending on the morphological requirements of the final sample. In this study, a cylindrical

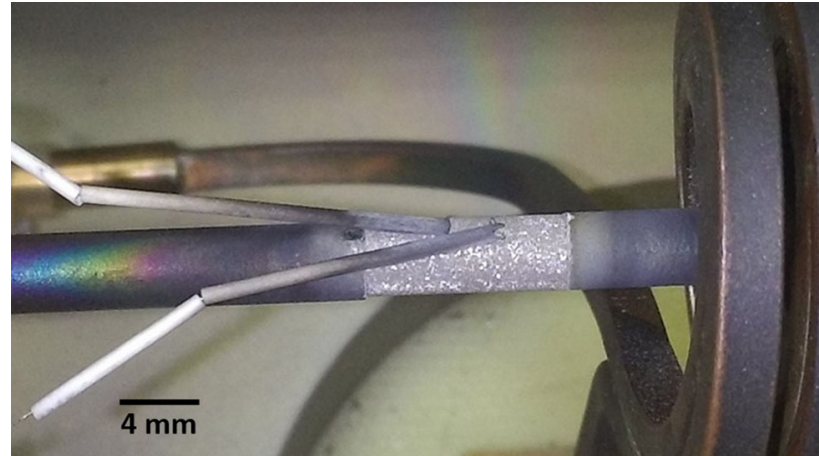

Fig. $24 \mathrm{~mm}$ diameter sample with the thermocouples attached inside the dilatometer

mold of $30 \mathrm{~mm}$ diameter and $100 \mathrm{~mm}$ length was used (see Fig. 1a).

The melting procedure was carried out three times to ensure that a homogeneous composition was reached. The bars were hot forged to a diameter of $14 \mathrm{~mm}$ (see Fig. 1b). Subsequently, normalization was performed prior to dilatometry measurements: $14 \mathrm{~mm}$ diameter and $30 \mathrm{~mm}$ long bars of Alloys 1 and 2 of were placed in a furnace and heated to $1150{ }^{\circ} \mathrm{C}$ with a heating rate of $5{ }^{\circ} \mathrm{C} / \mathrm{min}$, then held at that temperature for half an hour and then cooled in air. From the center of these $14 \mathrm{~mm}$ diameter bars, samples of $4 \mathrm{~mm}$ diameter $\times 10 \mathrm{~mm}$ height were cut by wire electrical discharge machining, then grinded and finally used for dilatometry study (see Fig. 2). After machining, the samples were cleaned by immersion in ethanol inside an ultrasound bath (to remove dirt and oils from the surface of the samples) and, just before the test, they were cleaned again with ethanol.

Figure 3 shows the microstructure before dilatometry experiments. Alloy 1 shows a ferrite and martensite microstructure, while Alloy 2 shows an austenitic microstructure.

Simulations were performed with JMatPro to determine solidus and liquidus temperature of the alloys in order to define the maximum heating temperature of the dilatometry measurements for the two low-density alloys (see Fig. 4).

Dilatometry was performed in a BÄHR DIL805L highvacuum dilatometer. Based on JMatPro estimates, the specimens were heated to a temperature at least $100{ }^{\circ} \mathrm{C}$ below the solidification temperature of each steel. To control the temperature, a thermocouple was welded to the surface (see Fig. 2), which allows the heating and cooling rates to be regulated.

The test conditions were as follows: heating at $3{ }^{\circ} \mathrm{C} / \mathrm{s}$ up to $1100{ }^{\circ} \mathrm{C}$ for Alloy 1 and up to $1050{ }^{\circ} \mathrm{C}$ for Alloy 2, holding at that temperature for $5 \mathrm{~min}$ and then controlled cooling at 0.01 ${ }^{\circ} \mathrm{C} / \mathrm{s}$. The test time for the samples was approximately $25 \mathrm{~h}$ to cool from the heating temperature to $200{ }^{\circ} \mathrm{C}$. 

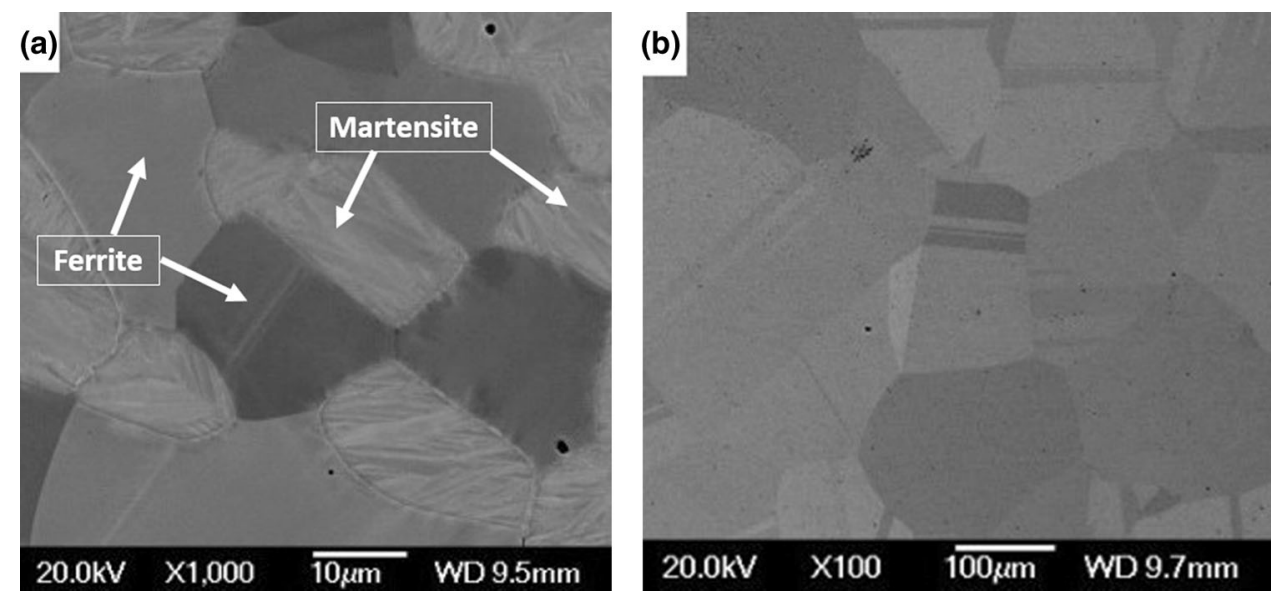

Fig. 3 Alloy 1 presents a ferritic and martensitic microstructure approximately 50\% each (a) and Alloy 2 presents a $100 \%$ austenitic microstructure (b)

The images in Fig. 3, 6(a), 7(a), 8, 9 and 11 were obtained with a JEOL JSM-7000F scanning electron microscope. The images in Fig. 12 and 14 were obtained with a ZEISS MERLIN scanning electron microscope. x-ray diffraction (XRD) measurements in Fig. 10 were performed with a Bruker D8 Discover 150 diffractometer equipped with a Cr Twist tube.

\section{Results and Discussion}

For the dilatometry study, $4 \mathrm{~mm}$ diameter samples were taken from the inside of the $14 \mathrm{~mm}$ diameter normalized samples. After the dilatometry tests, the heating and cooling curves of alloy 1 and its derivatives are shown in Fig. 5.

The dilatometry curves in Fig. 5 do not show a clear phase change and the slopes are not straight, which is indicative of a continuous transformation between two phases coexisting over a wide temperature range. It appears that on heating a slightly more pronounced change appears around $750^{\circ} \mathrm{C}$, which, according to JMatPro calculations (see Fig. 4a) is associated with the transformation of ferrite to austenite. On cooling, it appears that the most pronounced change occurs around 650$700^{\circ} \mathrm{C}$, perhaps due to the formation of the Kappa phase; again according to JMatPro calculations (see Fig. 4a).

The dilatometry curves for Alloy 2 were not plotted correctly due to the detachment of the thermocouple from the sample surface during the measurement. The reason for the thermocouple detachment will be explained in detail at the end of this section.

When analyzing the samples after dilatometry, the creation of a thick outer layer was observed (see Figs. 6a and 7a). The compositional difference between the surface and the inner part was very large after dilatometry tests. To measure this compositional gradient, semi-quantitative EDX analysis was performed on both samples. The results are presented in Fig. 6(b) and 7(b).

A variation in Mn content is observed in both samples. The $\mathrm{Mn}$ content is close to zero at the surface and increases continuously until it reaches a maximum at the interface of the inner zone, where it rises sharply to the nominal $\mathrm{Mn}$ percentage. This behavior is, especially noticeable in Alloy 2.
The thickness of the gradient layer is 115 microns for Alloy 1 and 70 microns for Alloy 2. This compositional gradient has created a completely different microstructure between the inside and outside of the samples.

Electron Backscatter Diffraction (EBSD) and x-ray diffraction (RXD) measurements were performed on the samples to identify the phases presented in the microstructures of the samples in Fig. 6a and 7a. These results are presented in Fig. 8 and 9. The Kappa phase was not indexed during the EBSD measurements due to the small size of its precipitates.

The graphs of the XRD measurements are shown in Fig. 10. The microstructure of the samples is textured due to deformation during the forging process.

In the case of Alloy 1, the outer layer is formed by a structure with large ferrite grains, while in the inner part two phases are present. These two phases are ferrite and austenite and can be distinguished in the compositional graph in Fig. 6(b), as well as in the EBSD images in Fig. 8. The ferritic grains are richer in aluminum and have less manganese, while the austenitic grains are richer in manganese and have less aluminum. The measured oscillations in composition match perfectly with the position of the grains of the different phases.

In the case of Alloy 2, the surface layer is composed of large ferrite grains, as both alloys have the same composition on the surface, and the inner part is formed by large austenitic grains (see Figs. 7 and 9) with some precipitates within these big grains and at the grain boundaries.

According to the shape of the precipitates (see Fig. 11), their composition (see Table 2) obtained by EDX analysis and XRD results (see Fig. 10), these precipitates are expected to be the Kappa phase or similar.

During each of the dilatometry measurements, a tantalum plate was introduced into the dilatometer chamber to collect the possible deposits generated during the experiment. Tantalum was chosen because of its different chemical composition compared to the alloys studied. Over the tantalum plate, there was a continuous and abundant deposit with the appearance of viscous or semi-liquid film that forms gravity waves (see Fig. 12). After each test, these deposits were analyzed by EDX. In Table 3 there is a comparison of the percentage of $\mathrm{Mn}$ and $\mathrm{Al}$ 
Fe-5.8Al-3.5Mn-0.35C wt(\%)

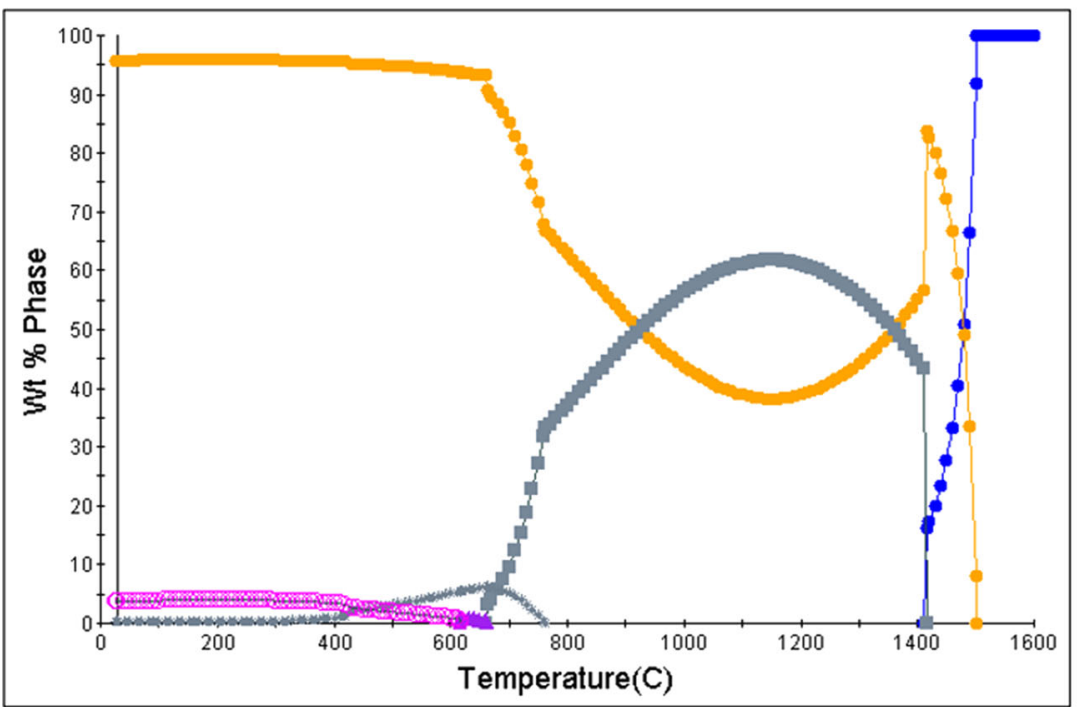

(a)

Fe-10Al-30Mn-1.3C wt(\%)

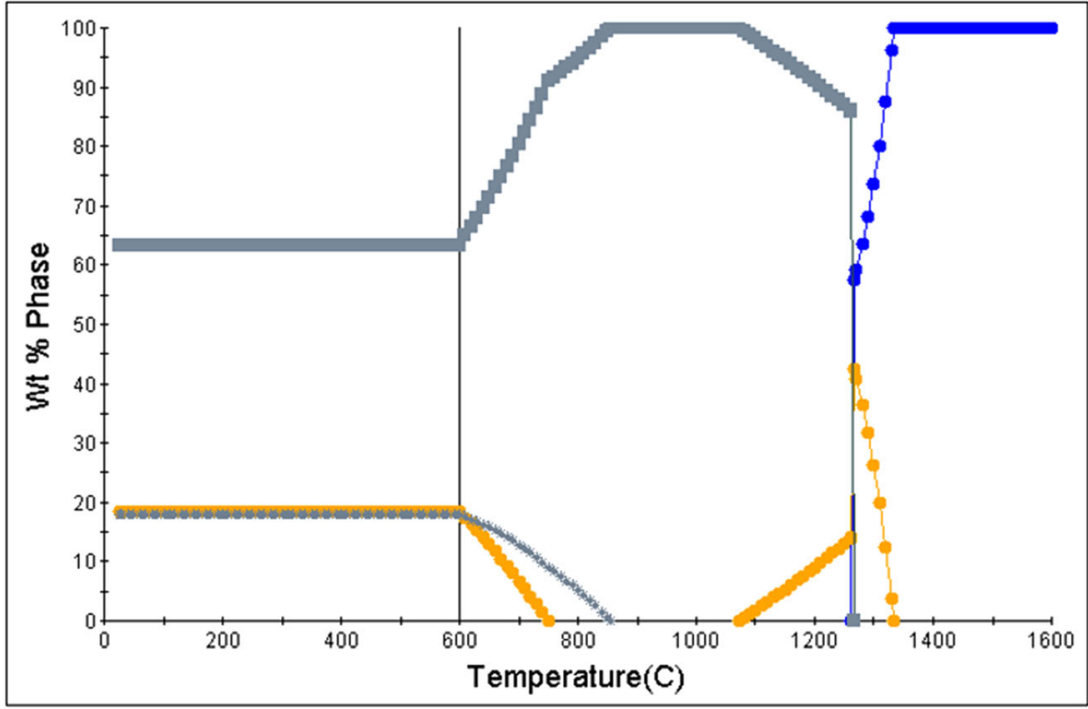

OLIQUID

(b)

Fig. 4 Phases present at different temperatures obtained with JMatPro for Alloy 1 (a) and Alloy 2 (b)

found over the tantalum plate deposits. The percentage of Mn found proves that there is a greater evaporation of this element when compared with Al. In the case of Alloy 1, there is no Al found and for Alloy 2 the Mn percentage found in the deposits is more than 5 times higher the $\mathrm{Al}$, while in the sample this percentage is only 3 .

The deposits in the dilatometer chamber present the same elements in their composition as the alloys measured, although with a higher proportion of manganese. The amount of manganese collected on the tantalum plate is higher for Alloy 2 due to its higher content of this element although the dilatometry was performed at lower temperature.

Due to the topology of these deposits (see Fig. 12), a semiliquid condensation appears, which could have its origin in the sublimation of the metallic elements on the surface of the dilatometry specimen.
The increase in manganese content in the deposits indicates that manganese evaporates at a higher rate than iron and aluminum.

In both alloys, there is a remarkable alteration of the chemical composition in the surface layer. The layer is enriched in $\mathrm{Fe}$ and $\mathrm{Al}$ and is depleted in $\mathrm{Mn}$ by diffusion and evaporation phenomena ranging from 70 to 115 microns.

These results are in good agreement with those of Catteau et al. (Ref [25]). They performed vacuum dilatometry experiments on a $0.35 \mathrm{C}-1.2 \mathrm{Mn}-0.7 \mathrm{Cr}-0.1 \mathrm{Mo}-0.1 \mathrm{~V}$ (in mass \%) steel, austenitized at $1150{ }^{\circ} \mathrm{C}$ for $3 \mathrm{~min}$, rapidly cooled to $600{ }^{\circ} \mathrm{C}$, held for $25 \mathrm{~min}$, and then gas quenched to room temperature. They also observed the evaporation of $\mathrm{Mn}$ to a depth of 10 microns.

This change in the microstructure of the surface layer can cause cracking problems when producing low-density alloys 


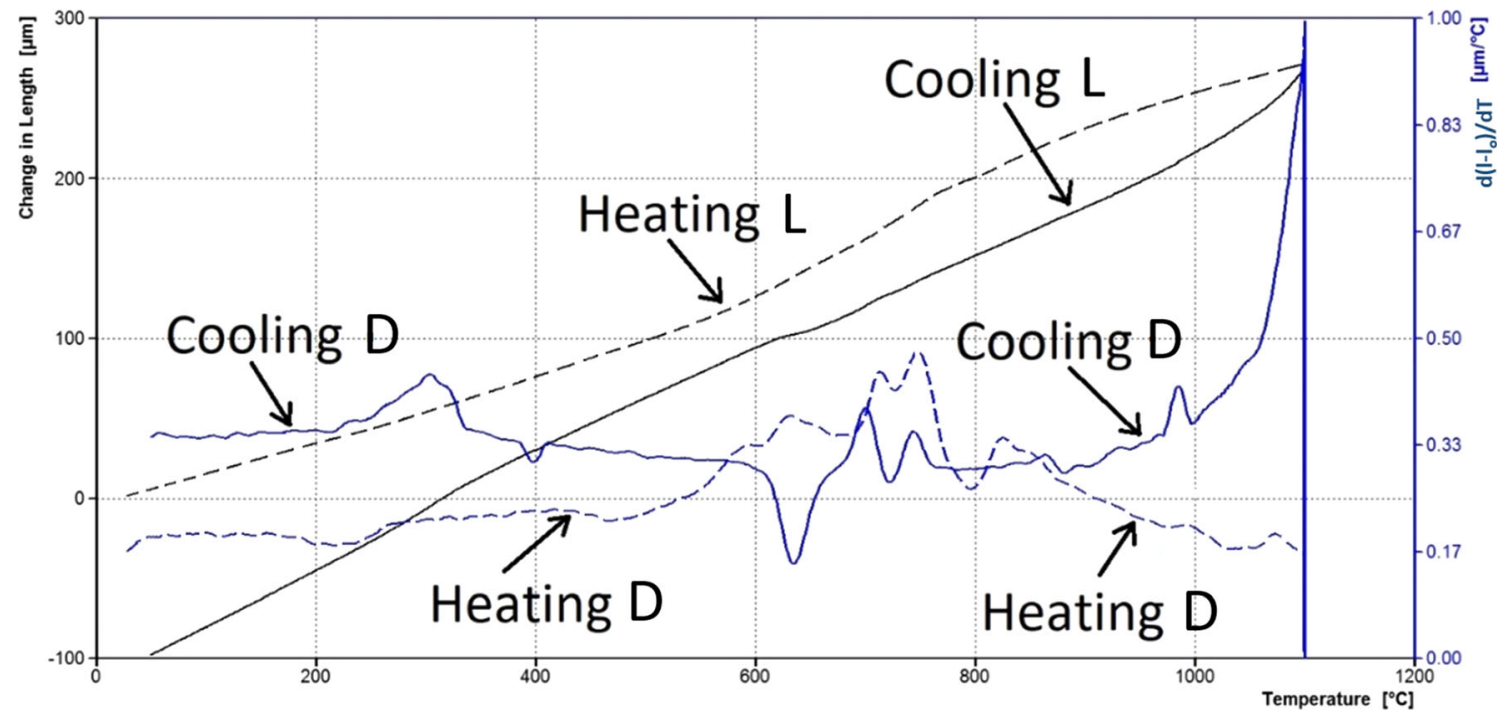

Fig. 5 Dilatometry length curves of the heating (Heating L dash line) and cooling (Cooling L continuous line) of Alloy 1 and its derivatives (Heating D dash line and Cooling D continuous line)
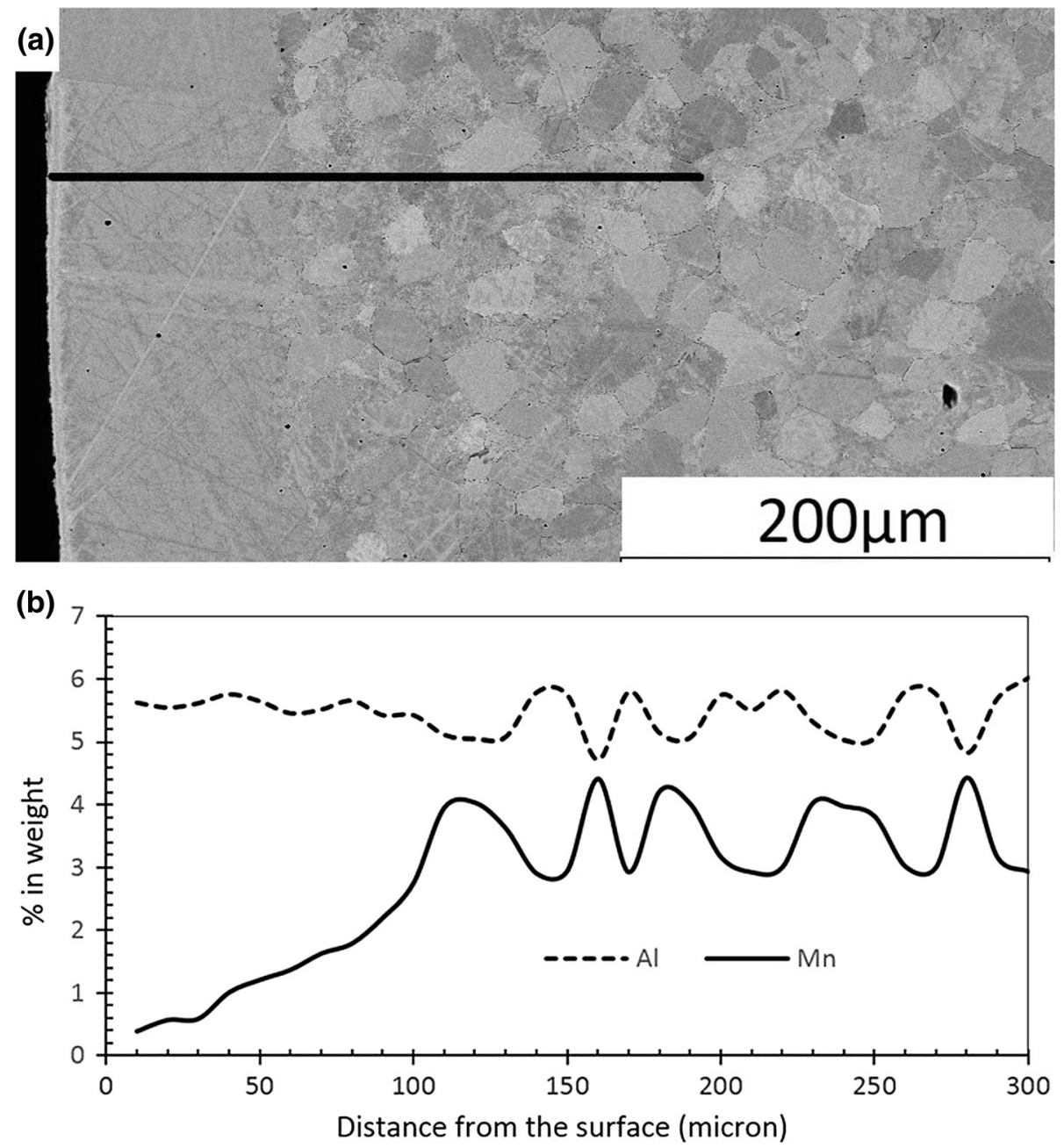

Fig. 6 Image of SEM (a) and semi-quantitative EDX of the compositional gradient of $\mathrm{Al}$ and Mn content following the black line from the surface to the inner part for Alloy 1 (b) 


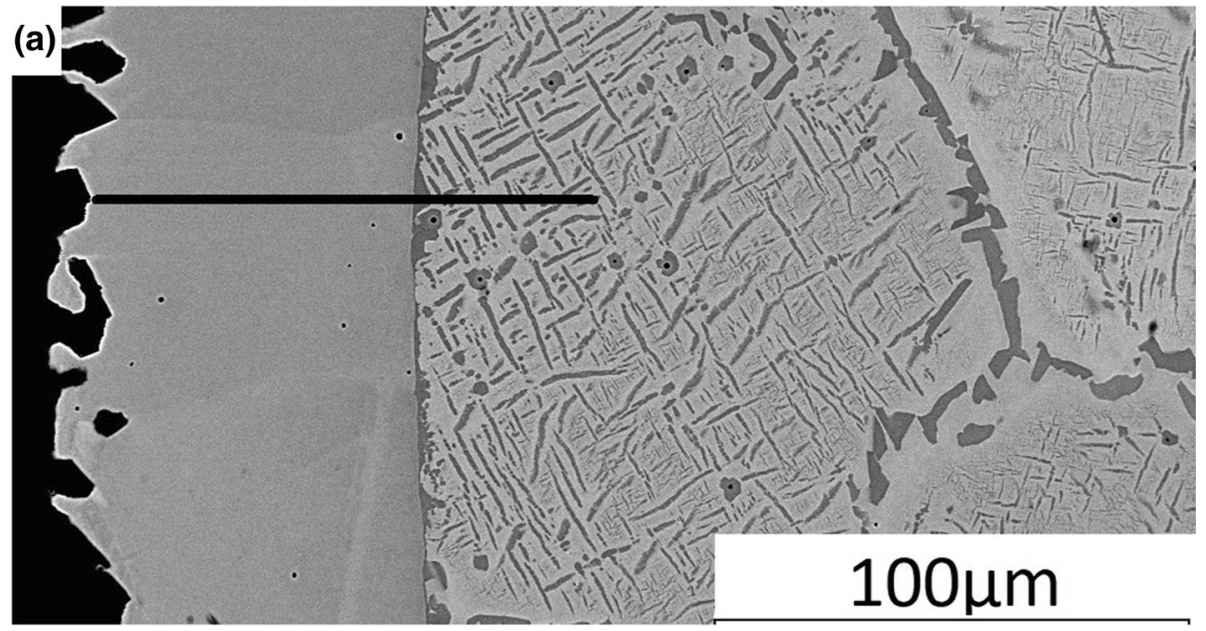

(b)

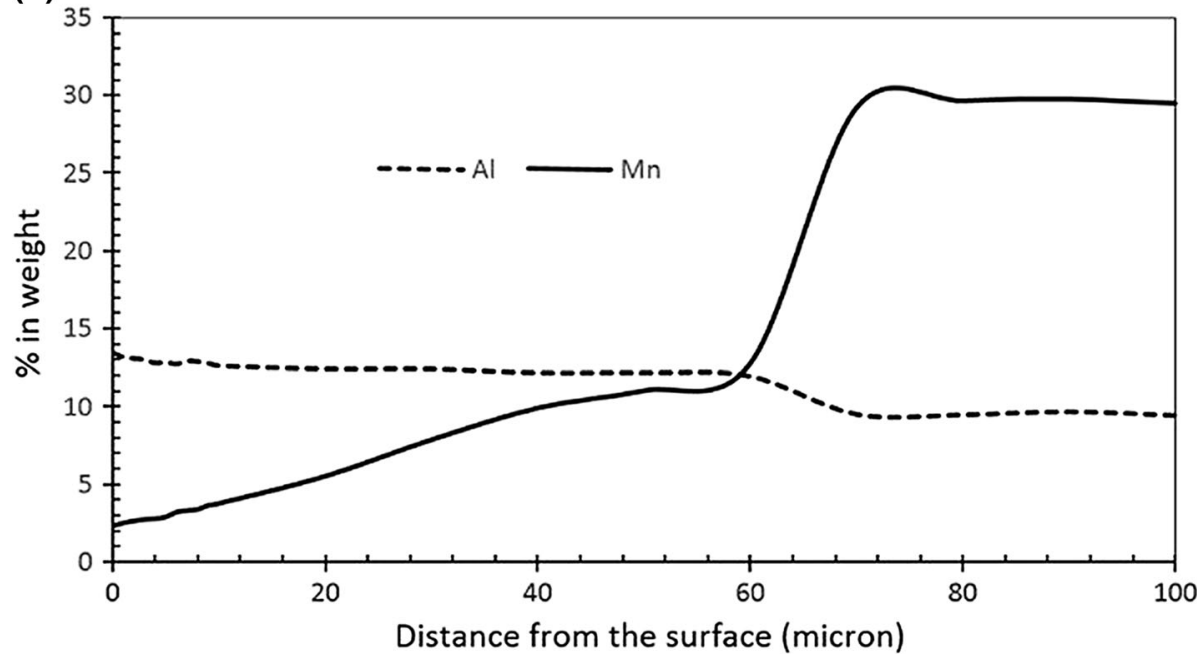

Fig. 7 Image of SEM (a) and semi-quantitative EDX of the compositional gradient of $\mathrm{Al}$ and $\mathrm{Mn}$ content following the black line from the surface to the inner part for Alloy 2 (b)

using current industrial processing routes, as reported by S. Chen et al. (Ref 28).

Theoretical calculations were performed to understand the relationship between the Mn diffusion distance and the depth of the depleted zone. Mn profiles were then calculated for both alloys using the second Fick diffusion equation according to (Ref 26).

The data used for these calculations are as follows:

For Alloy 1: Mn content $=3 \%$, Heating temperature $=$ from $293 \mathrm{~K}$ to $1373 \mathrm{~K}$, Heating rate $=3{ }^{\circ} \mathrm{C} / \mathrm{s}$ (360 sec heating time), Holding time $=300 \mathrm{sec}$, Cooling rate from 1373 to $473 \mathrm{~K}=$ $0.01{ }^{\circ} \mathrm{C} / \mathrm{s}(90.000 \mathrm{sec}$. cooling time), $\mathrm{R}(\mathrm{J} / \mathrm{mol} \cdot \mathrm{K})=8.31$, Preexponential factor $D_{0}\left(\mathrm{~m}^{2} / \mathrm{s}\right)=9.60 \mathrm{E}-07$, Activation energy for diffusion $\mathrm{Q}(\mathrm{kJ} / \mathrm{mol})=222\left(\mathrm{D}_{0}\right.$ and $\mathrm{Q}$ taken from Table 2 in (Ref 29)).

For Alloy 2: Mn content $=30 \%$, Heating temperature $=$ from $293 \mathrm{~K}$ to $1323 \mathrm{~K}$, Heating rate $=3{ }^{\circ} \mathrm{C} / \mathrm{s}$ (343 sec heating time), Holding time $=300 \mathrm{sec}$, Cooling rate from 1323 to $293 \mathrm{~K}=$ $0.01{ }^{\circ} \mathrm{C} / \mathrm{s}(85.000 \mathrm{sec}$. cooling time $), \mathrm{R}(\mathrm{J} / \mathrm{mol} \cdot \mathrm{K})=8.31$, Preexponential factor $D_{0}\left(\mathrm{~m}^{2} / \mathrm{s}\right)=7.30 \mathrm{E}-06$, Activation energy for diffusion Q $(\mathrm{kJ} / \mathrm{mol})=242\left(\mathrm{D}_{0}\right.$ and $\mathrm{Q}$ taken from Table 2 in (Ref 30)).

Theoretical Mn content for the dilatometry samples of Alloy 1 and Alloy 2 is plotted in Fig. 13.

The difference between the depleted zones of the two alloys is shown in Fig. 13. The manganese depleted distance for Alloy 1 is twice the zone obtained for Alloy 2. This result aligns with the experimental results presented in this work and indicates a higher diffusivity of manganese for Alloy 1 compared to Alloy 2. The theoretically calculated manganese profiles are smaller in terms of depths of the depleted zones for both alloys when compared to the physical dilatometry experiments. This difference can be attributed to the lack of data in the scientific literature for accurate diffusion coefficients for the alloys studied in this work. In addition, phase transformations in our studied alloys may influence the diffusion of $\mathrm{Mn}$ and the obtained depletion depth.

A second phenomenon was occurred during dilatometry measurements on these low-density alloys. Smaller ferrite grains were detached on the surface of the sample (Fig. 14a). 

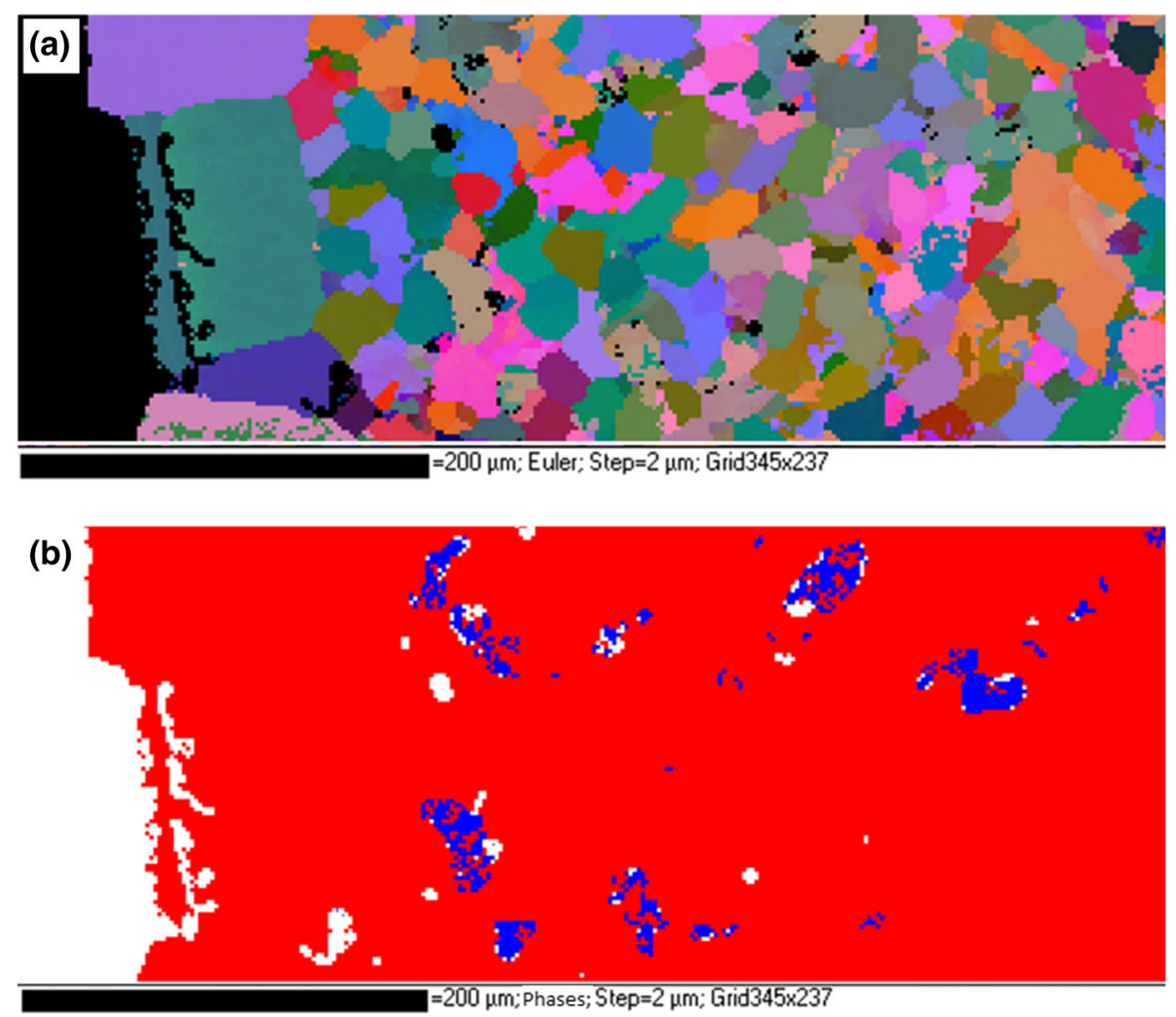

Fig. 8 EBSD results for Alloy 1 with a step size of 2 micron. Euler angles orientations of the grains (a) and indexed phases (mainly ferrite and some austenite) (b)
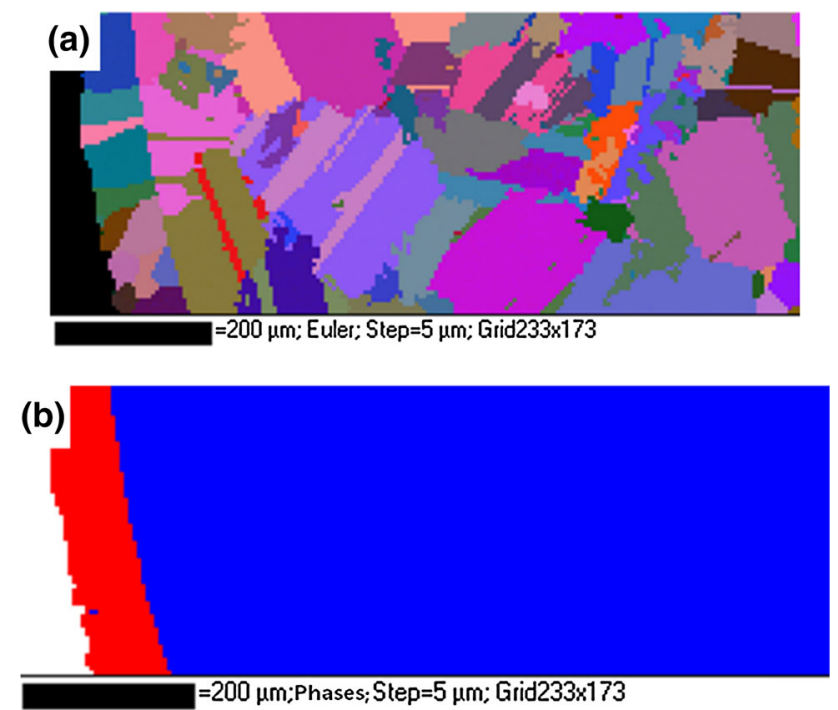

Fig. 9 EBSD results for Alloy 2 with a step size of 5 micron. Euler angles orientations of the grains (a) and indexed phases (ferrite in the exterior and austenite inside) (b)

This phenomenon occurs in both alloys, but is more pronounced in Alloy 2, with a higher Al content on the surface.

A rough, shiny layer appears on the entire surface of the samples (Fig. 14b). Polygonal cells with sharp edges were

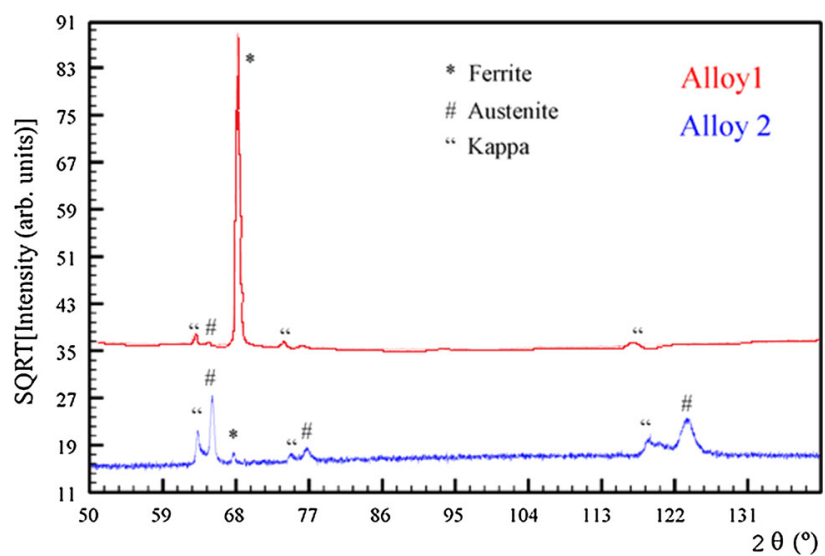

Fig. 10 XRD graphs of the phases present for the Alloy 1 (top) and Alloy 2 (bottom)

observed under the microscope (Fig. 14c). According to EDX results, they are formed by $\mathrm{Fe}-\mathrm{Al}$ with traces of manganese. There is also oxygen in the sample, which is present in the dilatometer chamber, as shown in Table 3.

The effect of migration and evaporation of $\mathrm{Mn}$ in the outermost layer makes it practically possible to form an Fe-Al alloy.

According to the Fe-Al phase diagram (see Fig. 15), at high temperature the ferrite is stable (with a minimum $\mathrm{Al}$ content of 


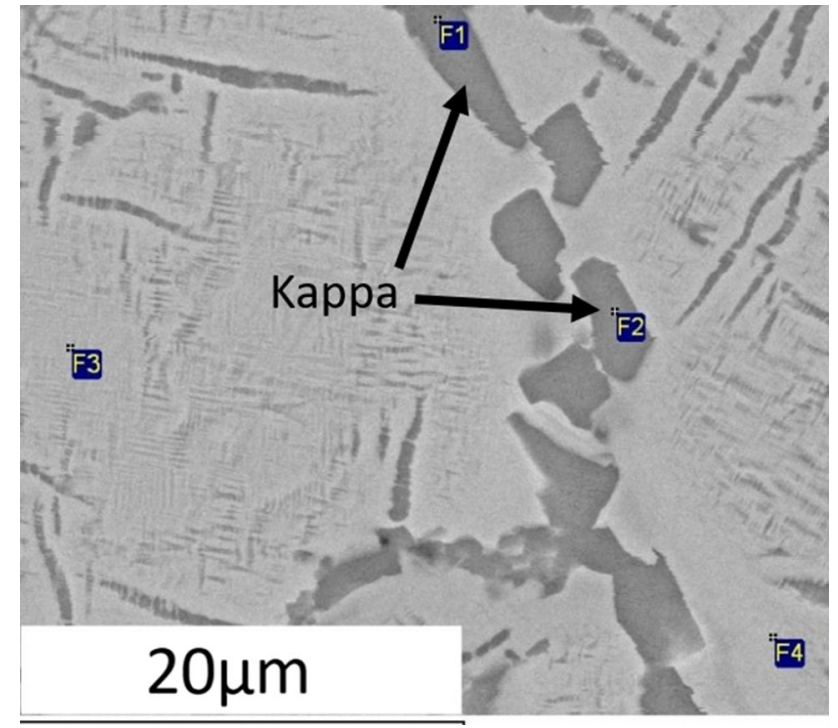

Fig. 11 Microstructure of the inner part of Alloy 2. Austenite matrix with Kappa phase precipitates

$1.95 \%$ ) and so is the $\mathrm{Fe}_{3} \mathrm{Al}$ phase. Above $1022{ }^{\circ} \mathrm{C}$ and, especially from $1092{ }^{\circ} \mathrm{C}$ the $\mathrm{Fe}_{3} \mathrm{Al}$ phase can decompose into other aluminum enriched phases. At $\mathrm{T}<1215{ }^{\circ} \mathrm{C}\left(1171{ }^{\circ} \mathrm{C}\right)$ the $\mathrm{Fe}_{3} \mathrm{Al}$ phase can segregate liquid $\mathrm{Al}$. Therefore, the outermost surface layer may be in the above conditions at $\mathrm{T}$ $>1100{ }^{\circ} \mathrm{C}$ and segregate phases that are either liquid, limiting the cohesion of the steel and facilitating the detachment of grains from the outermost surface layer. As mentioned at the beginning of this section when presenting the dilatometry results, the detachment of the surface grains may be the reason for the disconnection of the thermocouple from the surface of Alloy 2 during the performance of the dilatometry measurement. This detachment of the thermocouple made it impossible to obtain the complete dilatometry curve.

Although Alloy 2 was heated up to $1050{ }^{\circ} \mathrm{C}$ this temperature may be higher when the pressure decreases (Ref 31). Their study concludes that the transition temperature of delta iron to liquid increases with pressure based on the ClausiusClapeyron formula. In this study the pressure decreases with vacuum inside the dilatometer chamber, so it is expected that the transition temperature of delta iron from solid to liquid also decreases.

\section{Conclusions}

Manganese migration and subsequent evaporation were observed in the two low density alloys examined by vacuum dilatometry measurements. This manganese migration produced a thick layer on the outer section of the samples with a
Table 2 Chemical composition (wt\%) of different phases present in the inner part of Alloy 2

\begin{tabular}{lrlll}
\hline & Al & Si & Mn & Fe \\
\hline F1 & 11.85 & 0.1 & 31.8 & 56.25 \\
F2 & 11.76 & 0.09 & 31.59 & 56.55 \\
F3 & 9.57 & 0.27 & 29.16 & 61 \\
F4 & 9.27 & 0.23 & 29.32 & 61.18 \\
\hline
\end{tabular}

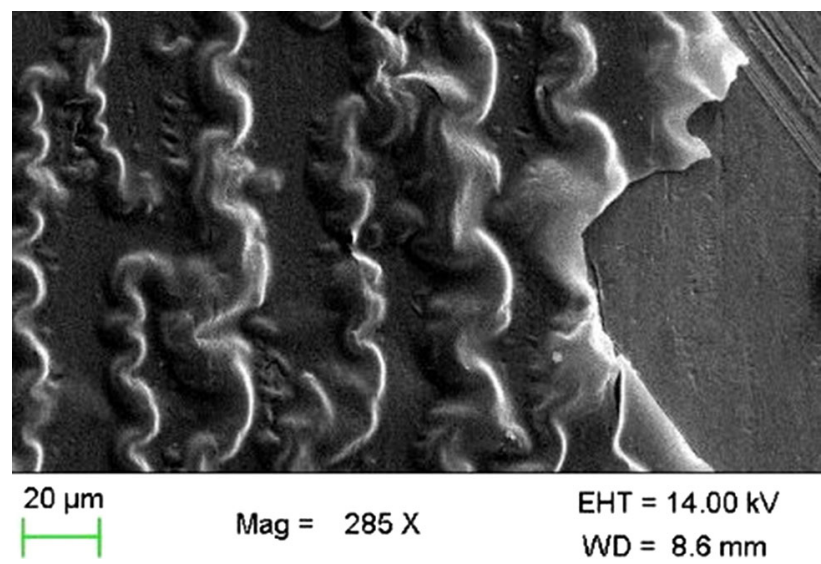

Fig. 12 Deposits collected on the tantalum plate inside the dilatometry chamber after testing Alloy 2 at $1050{ }^{\circ} \mathrm{C}$ with a cooling rate of $0.01{ }^{\circ} \mathrm{C} / \mathrm{s}$

Table 3 Al and Mn content of the deposits over the tantalum plate of the dilatometry chamber in \% of weight after testing Alloy 1 at $1250{ }^{\circ} \mathrm{C}$ and Alloy 2 at $1050{ }^{\circ} \mathrm{C}$ with a cooling rate of $0.01{ }^{\circ} \mathrm{C} / \mathrm{s}$

\begin{tabular}{lll}
\hline & Al & Mn \\
\hline Alloy 1 deposit & & 8.76 \\
Alloy 2 deposit & 1.8 & 9.54 \\
\hline
\end{tabular}

heterogeneous composition gradient that created a different microstructure on the surface. This layer with different composition and properties of the bulk material can grow up to $0.11 \mathrm{~mm}$ for dilatometry experiments with a manganese content of $30 \%$ and a cooling rate of $0.01{ }^{\circ} \mathrm{C} / \mathrm{s}$, affecting up to $10.7 \%$ of the total volume of the $4 \mathrm{~mm}$ diameter samples. This compositional gradient could affect the conclusions of dilatometry measurements, leading to misinterpretation of the results when working with steel alloys with high manganese content. Sufficient diameter samples and shorter duration tests should be 


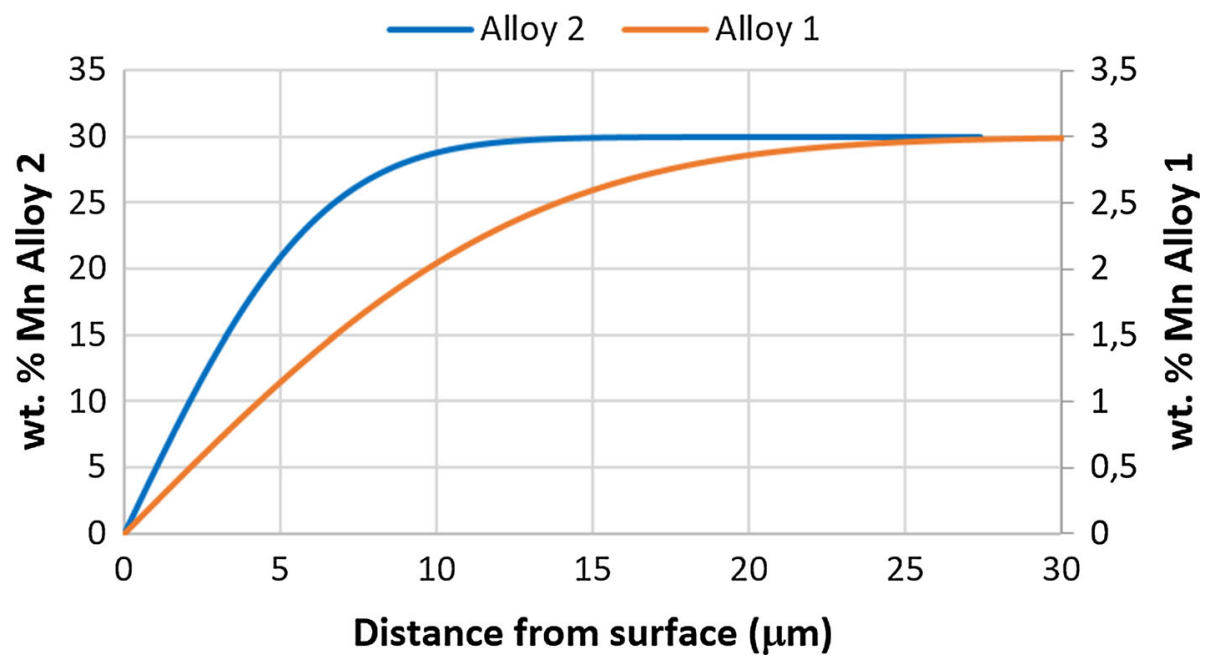

Fig. 13 Mn content after theoretical calculation for Alloy 1 and Alloy 2
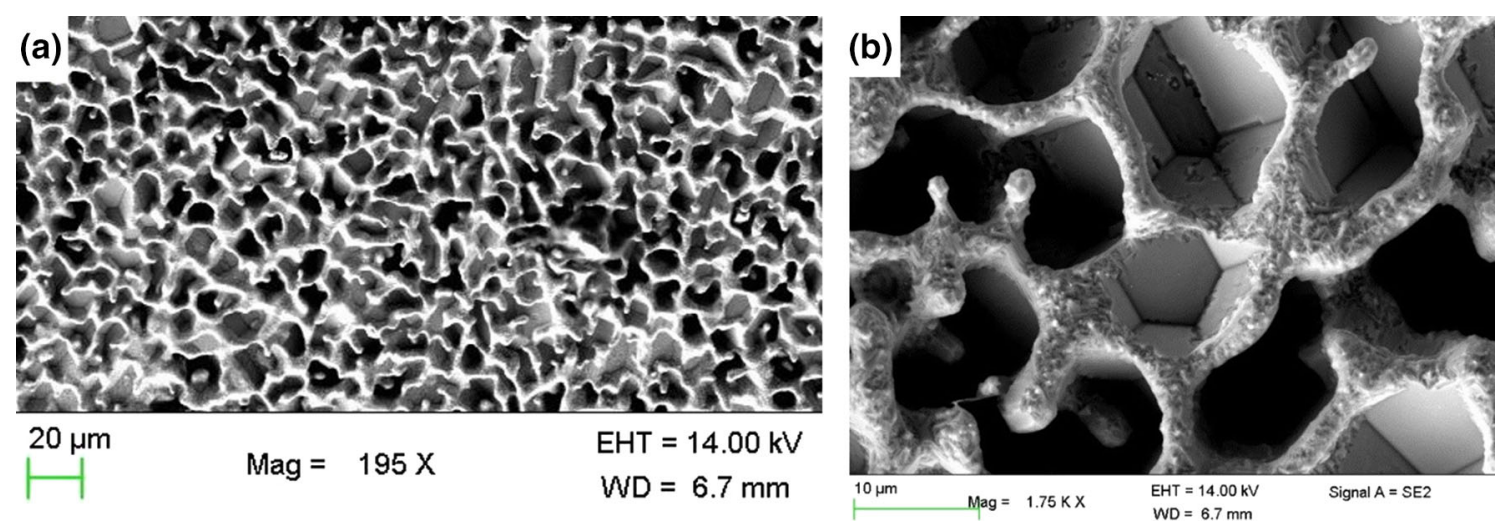

Fig. 14 Surface topography of the dilatometry specimen of Alloy 2 where the hollows of detached polygonal ferrite grains are observed (a, b)

prioritized whenever possible when performing dilatometry with high manganese steel alloys to minimize this problem.

Another phenomenon was observed in the two low density alloys, but especially in alloy 2. Due to the complete evaporation of $\mathrm{Mn}$ from the surface of the samples, a Fe and $\mathrm{Al}$ rich layer was created on the surface. This Fe-Al alloy can create decomposition of the surface particles at high temperatures. The melting of the newly created Fe-Al phase at high temperature can cause detachment of the surface grains from the large ferritic grains. This phenomenon can cause problems during dilatometry testing, such as detachment of the thermocouples from the surface of the samples. 


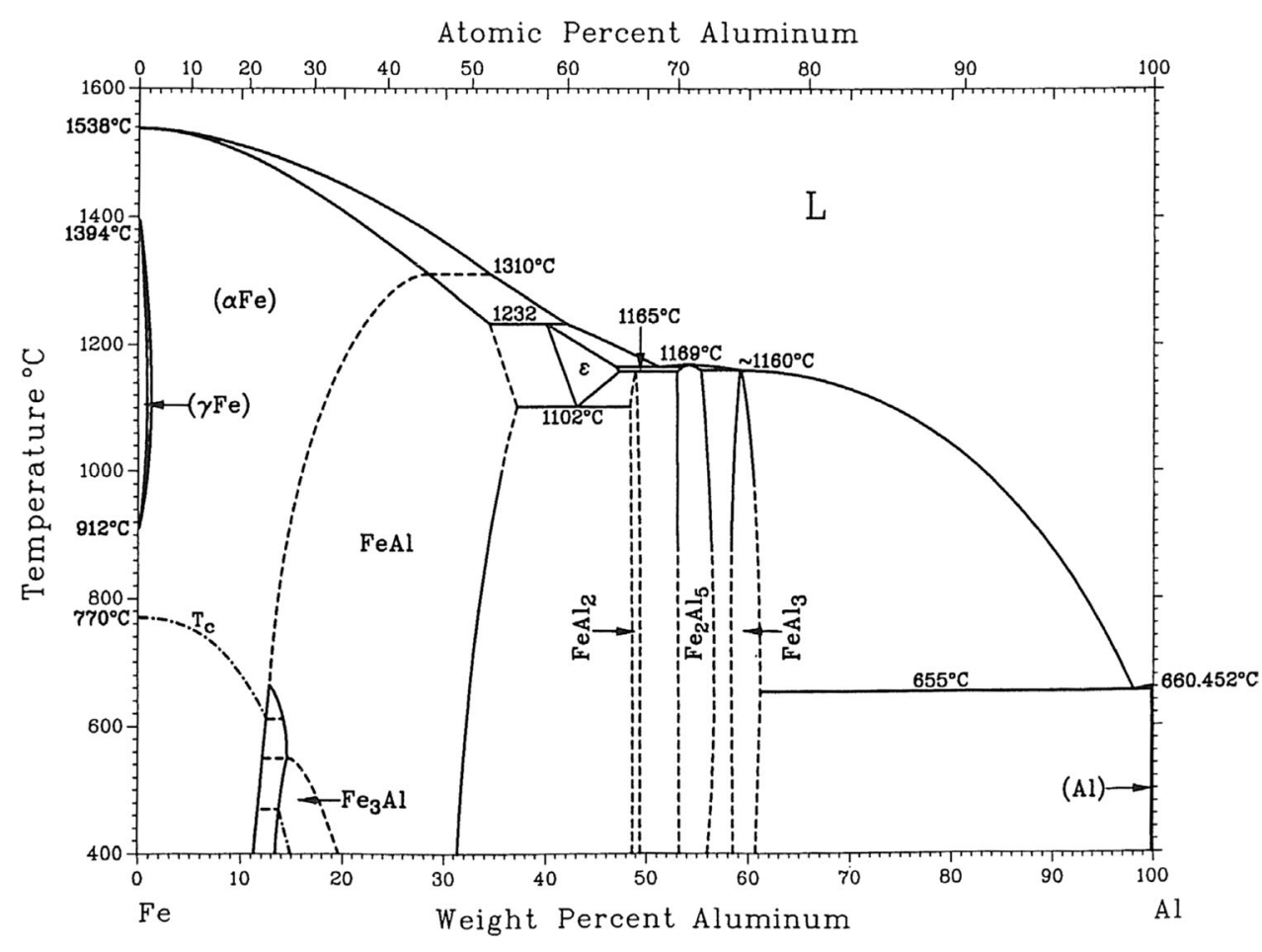

Fig. 15 Fe-Al diagram. Republished with permission of ASM International, from "Fe-Al Binary Phase Diagram," ASM Handbook, Vol. 3, Alloy Phase Diagrams, J.L. Murray, 2nd ed., H. Baker, Ed., 1992; permission conveyed through Copyright Clearance Center, Inc. (Ref 30)

\section{Acknowledgments}

The authors thank for technical and human support provided by SGIker of UPV/EHU and European funding (ERDF and ESF).

\section{Funding}

Open Access funding provided thanks to the CRUE-CSIC agreement with Springer Nature. This research was funded by the Basque Government under its ELKARTEK Research Program, KK-2016/00029-ABADE project and KK-2018/00016-COFADEN project.

\section{Open Access}

This article is licensed under a Creative Commons Attribution 4.0 International License, which permits use, sharing, adaptation, distribution and reproduction in any medium or format, as long as you give appropriate credit to the original author(s) and the source, provide a link to the Creative Commons licence, and indicate if changes were made. The images or other third party material in this article are included in the article's Creative Commons licence, unless indicated otherwise in a credit line to the material. If material is not included in the article's Creative Commons licence and your intended use is not permitted by statutory regulation or exceeds the permitted use, you will need to obtain permission directly from the copyright holder. To view a copy of this licence, visit http://creativecommons.org/licenses/by/4.0/.

\section{References}

1. G. Frommeyer and U. Brüx, Microstructures and Mechanical Properties of High-Strength Fe-Mn-Al-C Light-Weight TRIPLEX Steels, Steel Res. Int., 2006, 77, p 627-633

2. R. Rana, C. Lahaye and R.K. Ray, Overview of Lightweight Ferrous Materials-Strategies and Promises, JOM, 2014, 66, p 1734-1746

3. W. Korter and W. Ton, Arch. Eisenhuettenw, 1933, 7, p 365

4. J.L. Ham, R.E. Carin, Prod. Eng., 1958, p 52-59

5. H.J. Lai and C.M. Wan, The Study of Work Hardening in Fe-Mn-Al-C Alloys, J. Mater. Sci., 1989, 24, p 2449-2453

6. F.C. Chen, P. Li, S.L. Chu and C.P. Chou, Evidence of Strain-induced Martensitic Transformation in Fe-Mn-Al Austenitic Alloy Steels at Room Temperature, Scr. Metall. Mater., 1991, 25, p 585-590

7. Y.G. Kim, J.M. Han and J.S. Lee, Composition and Temperature Dependence of Tensile Properties of Austenitic Fe-Mn-Al-C Alloys, Mater. Sci. Eng. A, 1989, 114, p 51-59

8. S. Dong-Woo and N.J. Kim, Viewpoint set 53, Low-Density Steels, Scr. Mater., 2013, 68, p 337-338

9. C. Liu, C. T. W. Lahaye, High Strength and Low Density ParticleReinforced Steel With Improved E-Modulus and Method For Producing Said Steel, WO/2014/041136 A1, 2012

10. C. Liu, R. Rana, Low Density High Strength Steel and Method for Producing Said Steel, US Patent, Appl. 14241644 A1, 2014

11. C. Liu, R. Rana, High Strength Interstitial Free Low Density Steel and Method for Producing Said Steel, WO/2013/153114 A1, 2013

12. C. Liu, R. Rana, High Strength Bake-Hardenable Low Density Steel and Method for Producing Said Steel. WO/2013/124264, 2013

13. C. Liu, R. Rana, Low Density High Strength Steel and Method for Producing Said Stee. WO/2013/034317 A1, 2013

14. F. Del Frate, J. M. Mataigne, J. Staudte, A. Perlade, I. A. ZuazoRodriguez, Cold Rolled Steel Sheet, Method of Manufacturing and Vehicle, WO/2015/001367 A1, 2015 
15. S. Bano, C. Giraud, Very High Strength and Low Density, Hot-Rolled Steel Sheet and Manufacturing Process, US Patent, Appl. US7416615 B2, 2008

16. A. Perlade, O. Bouaziz, X. Garat, J. Drillet, J. L. Iriarte, Low Density Steel Having Good Drawability. US Patent, Appl. US/2017/0101694 A1, 2017

17. T.A. Kop, J. Sietsma and S. Van Der Zwaag, Dilatometric Analysis of Phase Transformations in Hypo-Eutectoid Steels, J. Mater. Sci., 2001, 36, p 519-526

18. C. García De Andrés, F.G. Caballero, C. Capdevila and L.F. Alvarez, Application of Dilatometric Analysis to the Study of Solid-Solid Phase Transformations in Steels, Mater. Charact., 2002, 48, p 101-111

19. J.Z. Zhao, C. Mesplont and B.C. De Cooman, Quantitative Analysis of the Dilatation During an Isothermal Decomposition of Austenites, Mater. Sci. Eng. A, 2002, 332, p 110-116

20. F.L.G. Oliveira, M.S. Andrade and A.B. Cota, Kinetics of Austenite Formation During Continuous Heating in a Low Carbon Steel, Mater. Charact., 2007, 58, p 256-261

21. R.A. Jaramillo and M.T. Lusk, Dimensional Anisotropy During Phase Transformations in a Chemically Banded 5140 Steel Part I: Experimental Investigation, Acta Mater, 2004, 52, p 851-858

22. R.A. Jaramillo and M.T. Lusk, Dimensional Anisotropy During Phase Transformations in a Chemically Banded 5140 Steel, Part II: Modeling, Acta Mater., 2004, 52, p 859-867

23. D.W. Suh, C.S. Oh, H.N. Han and S.J. Kim, Dilatometric Analysis of Austenite Decomposition Considering the Effect of Non-Isotropic Volume Change, Acta Mater., 2007, 55, p 2659-2669
24. G. Mohapatra, F. Sommer and E.J. Mittemeijer, A Temperature Correction Procedure for Temperature Inhomogeneity in Dilatometer Specimens, Thermochim. Acta, 2007, 453, p 57-66

25. S.D. Catteau, T. Sourmail and A. Moine, Dilatometric Study of Phase Transformations in Steels, Mater. Perform. Charact., 2016, 5, p 564-584

26. Y. Tomota, N. Sekido, S. Harjo, T. Kawasaki, W. Gong and A. Taniyama, In situ Observations of Transformation Behavior upon Heating for a 1.5Mn-1.5Si-0.2C Steel -Comparison Between Neutron Diffraction XRD EBSD and Dilatometry, ISIJ Int, 2017, 57, p 22372244

27. Y. Tomota, Y.X. Wang, T. Ohmura, H. Sekido, S. Harjo, T. Kawasaki, W. Gong and A. Taniyama, In situ Neutron Diffraction Study on Ferrite and Pearlite Transformations for a $1.5 \mathrm{Mn}-1.5 \mathrm{Si}-0.2 \mathrm{C}$ Steel, ISIJ Int., 2018, 58, p 2125-2132

28. S. Chen, R. Rana, A. Haldar and R. KumarRay, Current State of FeMn-Al-C Low Density Steels, Prog. Mater. Sci., 2017, 89, p 345-391

29. A.F. Smith and R. Hales, Diffusion of Manganese in Type 316 Austenitic Stainless Steel, Metal Science, 1975, 9(1), p 181-184

30. J. L. Murray, Fe-Al binary phase diagram. In Alloy Phase Diagrams; Baker, H., Ed.; ASM International: Materials Park, OH, USA, 1992, p 54

31. D.A. Porter and K.E. Easterling, Phase Transformations in Metals and Alloys, 3rd ed. CRC Press, USA, 2009

Publisher's Note Springer Nature remains neutral with regard to jurisdictional claims in published maps and institutional affiliations. 